\title{
Affiliate Marketing in SMEs: The Moderating Effect of Developmental Culture
}

\section{Zurina Patrick and Ong Choon Hee*}

Azman Hashim International Business School, Universiti Teknologi Malaysia, Johor Bahru, 81310, Malaysia

\begin{abstract}
The primary objective of affiliate marketing is to promote products or services via online distribution channels through third parties. However, its application has remained scarce despite being acknowledged as an efficient means of encouragement for SMEs to compete globally. This research adopts various technology adoption models to identify determining factors of intention to use affiliate marketing among SMEs. Developmental culture is included in the research model to assess its moderating effect. An online survey questionnaire has successfully obtained 180 usable responses for data analysis. The findings show that perceived usefulness, observability, and social influence are significant determinants of intention to use affiliate marketing. Developmental culture is found to moderate the results. Low developmental culture enhances the relationship between perceived usefulness and the intention to use affiliate marketing whereas high developmental culture strengthens the relationship between compatibility and the intention to use affiliate marketing. Implications of this study are discussed.
\end{abstract}

Keywords: Affiliate marketing, developmental culture, SMEs, technology adoption models

ARTICLE INFO

Article history:

Received: 04 January 2021

Accepted: 15 March 2021

Published: 30 June 2021

DOI: https://doi.org/10.47836/pjssh.29.2.27

E-mail addresses:

zurinapatrick@yahoo.com (Zurina Patrick)

ongchoonhee@gmail.com (Ong Choon Hee)

* Corresponding author

\section{INTRODUCTION}

The expansive use of the internet today has resulted in numerous changes in the business world, whereby the application can connect people via telecommunication device usage and allows its users to access the latest information in real-time (Maksimovic, 2018). Following its amplified utilization, affiliate marketing has thus emerged as one of the fast-growing online marketing 
tools. Despite it being underlined as a standard tool employed by organizations to conduct internet business globally, affiliate marketing has been associated with limited participation among SMEs in Malaysia (Beranek, 2018).

In this country, SMEs account for $98.5 \%$ of all sectors established (Department of Statistics Malaysia, 2018), wherein their expansion in the manufacturing sector has accumulated and thus reflected in the outstanding progress for the nation over the past 50 years. All-encompassing from its impact on the overall gross domestic product (GDP) to its contribution for job creation purposes, SMEs have created a clear path for economic prosperity. However, affiliate marketing in Malaysia has remained scarce despite being acknowledged as an efficient means of encouragement for SMEs to compete globally, thereby yielding improved sales and reducing their administrative costs (Newton \& Ojo, 2018). Past studies have addressed the adoption factors of online marketing platforms, such as search engine optimization (Zhang \& Cabage, 2017), email marketing (Karjaluoto \& Taiminen, 2015), and social media marketing (AlSharji et al., 2018). However, a discourse on affiliate marketing practices prevalent in a developing country like Malaysia has yet to be seen in the literature.

Previously, Haq (2012) has explored the element of consumer attitude toward affiliate programs or affiliate marketing, while Gregori et al. (2014) have explored the key variables affecting consumer trust in tourism-related affiliate websites. Similarly,
Suchada et al. (2018) have described their emphasis on factors included within the system of affiliate marketing and purchase intention. However, it must be noted that all three aforementioned studies are limited to India (Haq, 2012), the United Kingdom (Gregori et al., 2014), and Thailand (Suchada et al., 2018), respectively. Besides, these works have only investigated the perspective of a customer toward affiliate marketing, whereas the viewpoint of an organization is dismissed. Therefore, the need to identify and investigate factors that can influence the intention for SMEs in Malaysia to implement affiliate marketing cannot be denied.

\section{Theoretical Foundations}

TAM is a popular framework that suggests that the adoption of new technology is significantly driven by two determinants, which are perceived ease of use and perceived usefulness (Davis, 1989). Perceived usefulness is defined as the potential of the latest technology to help users perform and complete tasks more efficiently and effectively. In contrast, perceived ease of use refers to the function of the new technology, whereby the users can use it to carry out tasks. Several studies (Nagy 2018; Okafor et al., 2016; Ramachandran et al., 2019) related to TAM have revealed results that perceived usefulness is crucial compared to perceived ease of use in the context of online marketing, which has influenced the adoption of perceived usefulness in this study. Nevertheless, perceived ease of use does not affect the distribution of interactive 
online media technology for Malaysian SMEs (Okafor et al., 2016). The is the main reason why perceived ease of use was not included in the current research model.

DOI is referred to as the readiness of a person in adopting new technologies (Rogers, 2003). In addition to TAM, DOI also has an essential role in investigating the acceptance and adoption of technology, which consists of relative advantage, compatibility, observability, complexity, and trialability. Results from past studies on these attributes have confirmed compatibility, relative advantages, and observability are critical factors to use in adopting new technology (Lou et al., 2017; Zolkepli \& Kamarulzaman, 2015). Complexity and trialability instead were not suitable in technology adoption due to the reason that both are explaining the extent of testing that the technology can handle before full acceptance (Rogers, 2003). They do not affect the attitude or intention to adopt the technology (Lou, et al., 2017). Hence, this study selects only compatibility, relative advantages, and observability to be tested in the research model.

Apart from DOI, UTAUT is an alternative theory to explain user intention in adopting technology and subsequent usage behavior (Venkatesh et al., 2003). The four determinants in this model are effort expectancy, performance expectancy, social influence, and facilitating condition. Abbas et al. (2018) have analyzed the adoption of mobile banking in Pakistan using the UTAUT model, and argue that among the four determinants, social influence is the most critical of all. However, performance expectancy is synonymous with perceived usefulness and is, therefore, not be adopted in this study. Effort expectancy is the use of technology that can be considered as easy or difficult, which is similar to the perceived ease of use (TAM) and complexity (DOI). On the other hand, facilitating conditions are referred to as a situation when a person knows the organization will encourage the adoption of new technology but is found to be insignificant for adoption due to the effect of being captured by effort expectancy (Venkatesh et al., 2003). Hence, only social influence is selected from the UTAUT theory as it refers to the extent an individual feels essential for others to believe he or she needs to use a new system (Venkatesh et al., 2003).

Researchers believe that the role of moderating variables is crucial in designing a model for adopting technology (Tian et al., 2018; Venkatesh et al., 2003). Research conducted by Tian et al. (2018) shows that different types of organizational culture have different impacts on technological innovation. The competing values framework (CVF) developed by Quinn and Kimberly in 1984 embraced four different cultures, namely group culture, hierarchical culture, developmental culture, and rational culture. Conceptually, developmental culture is defined as an adhocracy culture based on change, risk-taking, and innovation (Quinn \& Spreitzer, 1991). An empirical study by J.-C. Lee et al. (2017) found that firms with high developmental cultures positively led to the enhanced 
implementation of new technology. This positive relationship is robust compared to the other dimensions of organizational culture (group, hierarchical, and rational) in the competing values framework (CVF). Following this revelation, this study thus opts for the introduction of developmental culture as a moderating variable in the designed research model.

\section{Affiliate Marketing}

In general, affiliate marketing is one of the online marketing platforms offered today, whereby a company will sign an agreement with a third party (i.e. individual or organization) to feature a link on the affiliate site (Dwivedi et al., 2017). The primary objective of affiliate marketing is to promote and sell products or services via other distribution channels, following which the purchase information is transmitted to the clients for the completion of the sale transaction. It is associated with the creation of transactions from online customers, which will result in commission generation in return (Fox \& Wareham, 2010). Theoretically, the core activities of affiliate marketing can be summarized as follows: First, an affiliate tries to direct potential customers to a client's website via the use of ad links. Second, these potential customers will perform an action necessary for the completion of the sale transaction. Finally, the client company rewards every action requested in order to conclude the sales, which are then traced back to the affiliates. This platform saves organizations time and effort in reaching their target customers and shares some of their revenues with the affiliates (Suryanarayana et al., 2019).

Fox and Wareham (2010) have proposed for SMEs involved in the e-commerce market to consider its implementation in their bid to increase sales. This is attributable to its well-known status as a highly costeffective type of online advertising channel versus other comparable platforms, which is due to its capacity for reducing the administrative costs associated with sales advertising. Recently, most research on affiliate marketing focused on in-house affiliate marketing (Beranek, 2019), sports betting (Houghton et al., 2020), the role of affiliate marketing on social media (Haikal et al., 2020), and different operating systems (Singhal \& Anand, 2021). However, factors that influence the intention to use affiliate marketing are still found to be lacking within the literature of online marketing and related research. Therefore, studies on affiliate marketing should be carried out extensively to contribute to the growing body of literature.

\section{Perceived Usefulness}

Perceived usefulness refers to the potential offered by technology for enhanced quality or performance of a working individual in an organizational context (Davis, 1989). In general, this component has long since been considered the most prominent driver for technology acceptance. For example, an innovative study by Ramachandran et al. (2019) on social media adoption among the SME service sector in Malaysia claimed 
that perceived usefulness was the most significant factor in behavioral intention. Meanwhile, S. Lee (2018) has investigated the varying ways a customer's continuous usage of a mobile app can be enhanced, which is underpinned by the technology adoption model. The study outcomes have specifically confirmed the positive influence of perceived usefulness toward mobile app utilization accordingly.

Parallel to the above works, Belete and Tsegaye (2018) have underlined the positive correlation between perceived usefulness and the adoption of a new internet banking system. In this context, evidence shows that whenever a new technology is perceived as useful by its users, their tendency for adopting the new system will increase. Besides, the work conducted by Haq (2012) has implemented a survey involving 300 respondents (i.e. consumers) from the cities of Hyderabad, Delhi, Bangalore, and Mumbai in India. As a result, confirmation was obtained regarding the significant effect of perceived usefulness on the respondents' intention to participate in online-based affiliate marketing programs. Hence, the aforementioned studies lead to the following hypothesis proposed:

H1. There is a significant relationship between perceived usefulness and the intention to use affiliate marketing.

\section{Relative Advantage}

Relative advantage is defined as the level at which the current technology is perceived as lower compared to the adoption of new technologies (Rogers, 2003). Meanwhile,
Mairura (2016) has noted that it is often viewed conceptually as the economic profitability, social prestige, or other benefits attained by an organization, whereas Jalali et al. (2019) have more recently postulated that it can affect the continuous implementation of technology. Furthermore, Shaltoni (2017) has positioned its significant correlation with internet marketing adoption in the context of Jordanian industrial organizations, wherein the findings indicate these industrial players' continued tendency for it to increase their customer value, reputation, and ability to reach new markets.

Moreover, Sun et al. (2018) have argued that SMEs are likely to adopt new technology if it comes along with greater benefits and good solutions for various business problems. In the context of Malaysia specifically, Zain et al. (2020) have provided evidence on the positive and significant relationship between relative advantage and the adoption of e-commerce by SME managers. This is supported by Zolkepli and Kamarulzaman (2015) via their research findings. They have underlined the notable influence of relative advantage toward the adoption of social media among Internet users, thus revealing the highly supported use of social media if benefits or relative advantage to do so are perceived. Additionally, affiliate marketing yields a greater relative advantage to business organizations and helps toward reaching a huge volume of customers, rendering it more likely for SMEs to be e-marketingoriented Hence, it is hypothesized that: 
$\mathrm{H} 2$. There is a significant relationship between relative advantage and the intention to use affiliate marketing.

\section{Compatibility}

Compatibility is commonly understood as the degree to which an innovation parallels and is consistent with prior practices, socio-cultural values, past experiences, and current needs. When the new technology is perceived to be in line with occupational values and expectations, a company will find itself more open to innovation. Regardless, Mbiadjo and Djeumene (2015) have posed arguments wherein the success of mobile marketing adoption is reliant upon its capacity to fulfill the user needs and exhibit the system and cultural compatibility. On top of this, the study by Samat et al. (2017) has described the contributory effect of compatibility to the adoption of social media marketing in Malaysia. Another empirical study by Zain et al. (2020) has found that compatibility had a positive and significant impact on the adoption of e-commerce by SME managers.

Meanwhile, the role of compatibility has been studied by Sandu et al. (2017) in predicting the adoption of Cloud-based services among SMEs, which results in a comprehensive explanation using the findings obtained. In contrast, the lack of technology compatibility has been associated with the possibility of its hindered adoption. Therefore, the new experience attained by users opting for the use of technology should be in line with their past experience and meet their current needs in order for the technology adoption to successfully take place. Based on the literature review above, it is hypothesized that:

H3. There is a significant relationship between compatibility and the intention to use affiliate marketing.

\section{Observability}

A study by Rogers (2003) eloquently defines observability as the extent to which the results of an innovation are visible to others, thereby referring to a stage wherein people can observe the positive results of technology usage accordingly. In simple words, a greater level of observability leads to an amplified acceptance and adoption of technology. This results in many scholarly attempts, such as the study by Chauhan et al. (2018) that has explored the factors influencing customer intention to utilize mobile applications in India. Here, the authors have noted that observability, in particular, increases the interest expressed by the residents to use mobile applications, whereas less observable applications are found to show slower progress in their adoption.

Meanwhile, the focus placed on Malaysia by Poorangi et al. (2013) has resulted in the significance of observability toward the adoption of e-commerce among SMEs. In this regard, technology plays a severely important role in the development of any company, especially those involved in the e-commerce market. Besides, a study on the implementation of green fertilizer technology within the Malaysian agriculture sector by Adnan et al. (2019) 
provided clear evidence on the significant relationship between observability and farmer's behavioral intention. Therefore, observability can be explained when it comes to the adoption of affiliate marketing in a manner wherein the management team in charge is able to perceive the benefits possibly induced by the technology to their business. Therefore, it is hypothesized that:

H4. There is a significant relationship between observability and the intention to use affiliate marketing.

\section{Social Influence}

The element of social influence refers to a level in which an individual perceives the importance of others to believe that they should use a system (Venkatesh et al., 2003). In the context of the current topic, a previous study conducted by Rahaman et al. (2018) has discovered a positive and direct relationship linking it with technology adoption. Besides, those involved in research works in this field have further agreed that social influence is an essential factor in the process of accepting new technologies (Cheung et al., 2011). For instance, a study conducted by Abdat (2020) has found that social influence significantly impacts the adoption of social media apps among Indonesian small and medium-sized enterprises. Nonetheless, an empirical study on the adoption of e-commerce in the SME sector by Punjab by Batra and Arora (2020) also revealed that social influence was a significant determinant.

Similarly, an investigation by Abbas et al. (2018) regarding the role of social influence has underlined its importance as the most significant factor among other comparable elements by implementing the UTAUT theory. Nevertheless, Venkatesh et al. (2003) are of the opinion that social influence can alter the beliefs held by one and further directs them into responding to social pressure in the process of deciding whether or not to adopt new technology. Additionally, it has been assessed across various fields of technology, rendering the perception of social influence being an important link in establishing the intention to use new technology (Suchada et al., 2018). Thus, the following hypothesis is suggested:

$\mathrm{H} 5$. There is a significant relationship between social influence and the intention to use affiliate marketing.

\section{Developmental Culture}

In general, developmental culture is among the cultural dimensions included in the Competing Values Framework (CVF), which was developed by Quinn and Kimberly in 1984. Theoretically, this element can be described as an adhocracy culture fundamentally underpinned by change, risk-taking, and innovativeness (Quinn \& Spreitzer, 1991). Subsequently, it is also characterized by a new idea of change, adaptability, innovation, growth, and resource acquisition accordingly (Cameron \& Quinn, 2011).

In line with the above notion, Merchant (2007) has explored the influence of cultural values on information technology (IT) acceptance, thus resulting in their claim 
underlining cultural dimension as the key variant for consideration in IT adoption due to its capability to support individual decisions and actions. Meanwhile, the study by J.-C. Lee et al. (2017) has highlighted the obvious need for an investigation into the role of developmental culture as a moderator in technology adoption. Here, they have argued that without developmental culture, SMEs will not find themselves to be in an environment that can lead them toward the adoption of new technologies. In relation to this finding, the scholarly work of Huang et al. (2013) has offered evidence of organizational culture and its role in moderating the relationship between power, trust, and the adoption of electronic supply chain management system (e-SCMS). Therefore, based on the above discussion, it is hypothesized that:

H6a. Developmental culture moderates the relationship between perceived usefulness and the intention to use affiliate marketing.

H6b. Developmental culture moderates the relationship between relative advantage and the intention to use affiliate marketing.

H6c. Developmental culture moderates the relationship between compatibility and the intention to use affiliate marketing.

H6d. Developmental culture moderates the relationship between observability and the intention to use affiliate marketing.

H6e. Developmental culture moderates the relationship between social influence and the intention to use affiliate marketing.

Figure 1 outlines the research model that guides this study.

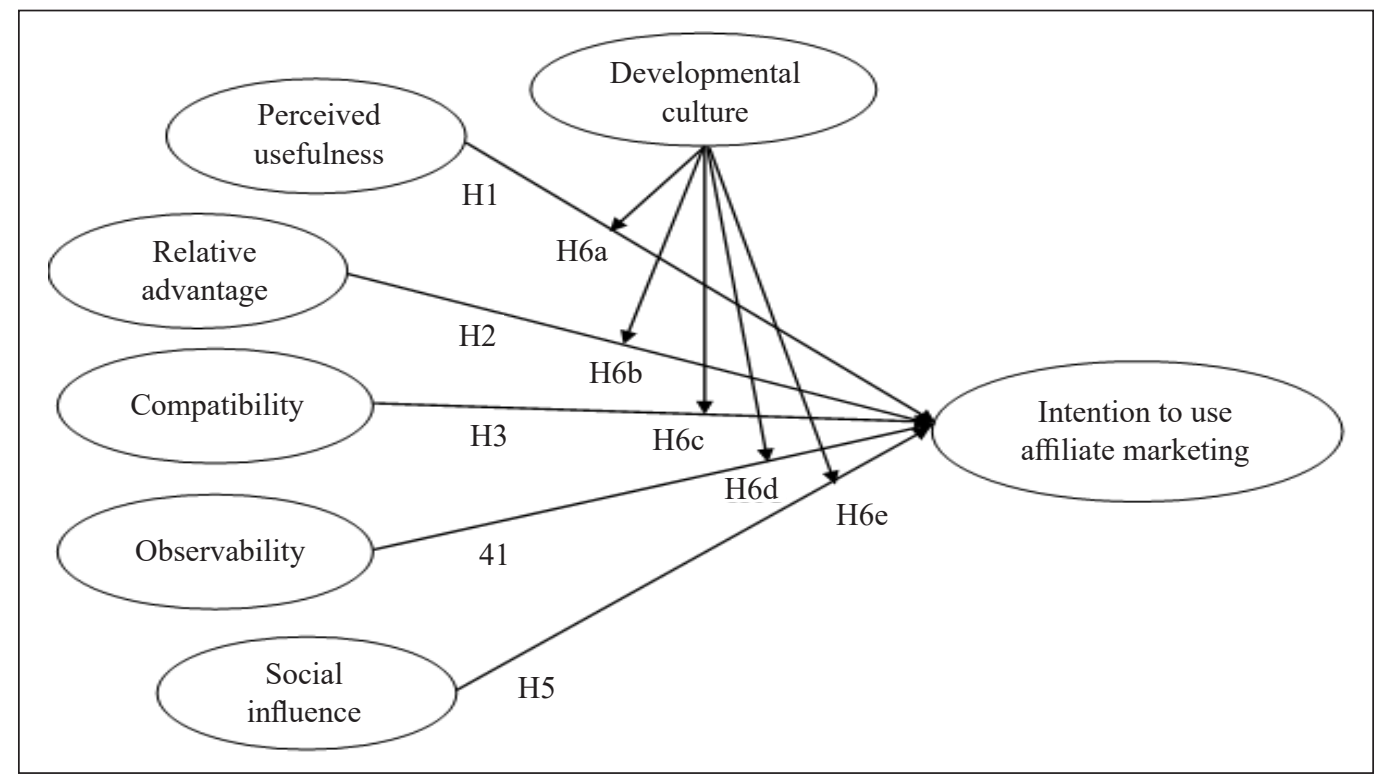

Figure 1. Research model 


\section{METHODS}

\section{Population and Sampling Method}

This research opted for SME manufacturers in Malaysia as the target population, with a focus on the top-four states of Selangor, Johor, WP Kuala Lumpur, and Perak. Based on the statistics provided by the Department of Statistics Malaysia, a total of 49,101 SME manufacturing establishments are recorded in Malaysia (SME Corporation Malaysia, 2018). However, the emphasis in this study resulted in engagement with 27,693 establishments only out of the total number, which was contributed by the states of Selangor (10,017), Johor (8,053), WP Kuala Lumpur $(5,254)$, and Perak $(4,369)$ accordingly. The selection of these states as the research sites was due to them having the highest number of SMEs involved in the e-commerce market (SME Corporation Malaysia, 2018).

Next, this study employed the stratified random sampling technique due to the nature of the population itself, which consisted of strata (i.e., four states). The process dictates the stratification of population, which is followed by selecting the research respondents via random sampling until the desired sample size is reached (Saunders et al., 2009). To determine the number of samples, Cohen's (1992) statistical power analysis sampling table was implemented with reference to the following criteria: significance level of $5 \%$, the statistical power of $80 \%$, and $\mathrm{R}^{2}$ value of at least 0.25 . The sampling criteria are henceforth referred to as the maximum number of arrows pointing at a construct. As a result, this study required 75 responses as the minimum amount of samples; however, 180 usable responses were collected for the purpose of data analysis.

\section{Measures}

Measures implemented for the study constructs were adopted from previous studies, which were subjected to minor modifications in line with the study scope. The questionnaire was developed and designed in the English language, wherein further details of its measures are included in Appendix 1. For construct measurement purposes, a 5-point Likert scale (i.e., strongly disagree, disagree, neutral, agree, and strongly agree) was utilized accordingly.

\section{Data Collection Procedure}

The current research was conducted to its completion by using a cross-sectional quantitative approach, whereby an online survey questionnaire was implemented to collect data from the respondents engaged. Copies of the survey questionnaire were sent to the respondents via their email address in which their particulars were obtained from the directory of the Federation of Malaysian Manufacturers (FMM). As a result, a total of 201 completed questionnaires were successfully gathered but only 180 responses were deemed usable for further analysis. PLS-SEM was used for data analysis. 


\section{RESULTS}

\section{Demographic Profiles}

The demographic profiles of study respondents are depicted in Table 1. Overall, the respondents who participated in this study were of varying positions, namely 46 managing directors/owners, 81 marketing/ sales managers, 11 IT managers, 8 operation managers, and 34 individuals of other managerial positions. A majority of them had more than 10 years of work experience (38.9\%), which was followed by those with 5 to 10 years of experience $(36.1 \%)$, and those with less than 5 years of experience (25\%). Most of the participating companies had been operating for more than 20 years $(48.9 \%)$, followed by 15 to 20 years (31.1\%), whereas the remaining 13.9\% had been established for 10 to 15 years and a small percentage within 5 to 10 years (6.1\%). Furthermore, a big percentage of the companies consisted of small enterprises (55.6\%) having 5 to 75 full-time employees (76.1\%) and sales turnover of RM300,000 to RM15 million (55.6\%). In contrast, medium enterprises constituted $44.4 \%$ of the companies and recorded sales turnover between RM15 million to RM50 million. All of the participating SMEs were located in four major states of Malaysia, namely Selangor (40.6\%), Johor (27.2\%), WP Kuala Lumpur (17.8\%), and Perak (14.4\%).

Table 1

Demographic profiles

\begin{tabular}{llcc}
\hline Description & \multicolumn{1}{c}{ Category } & Frequency $(\mathrm{n}=180)$ & Percentage (\%) \\
\hline Position & Managing Director/Owner & 46 & 25.6 \\
& Marketing/Sales manager & 81 & 45 \\
& Operation manager & 8 & 4.4 \\
& IT Manager & 11 & 6.1 \\
& Others & 34 & 18.9 \\
\hline Work experience & Less than 5 years & 45 & 25 \\
& 5 to 10 years & 65 & 36.1 \\
& More than 10 years & 70 & 38.9 \\
\hline Years of company & 5 to 10 years & 11 & 6.1 \\
establishment & 10 to 15 years & 25 & 13.9 \\
& 15 to 20 years & 56 & 31.1 \\
& More than 20 years & 88 & 48.9 \\
\hline Full-time employees & 5 to 75 & 137 & 76.1 \\
& 75 to 200 & 43 & 23.9 \\
\hline Sales turnover & RM300,000 to RM15 million & 100 & 55.6 \\
& RM15 million to RM50 million & 80 & 44.4 \\
\hline Location of the & Johor & 49 & 27.2 \\
company & WP Kuala Lumpur & 32 & 17.8 \\
& Perak & 26 & 14.4 \\
& Selangor & 73 & 40.6 \\
\hline
\end{tabular}




\section{Measurement Model Assessment}

A measurement model was established in this study to assess the outer loadings, internal consistency, convergent validity, and discriminant validity of the study constructs. Table 2 indicates that all outer loadings of the constructs exceed the value of .70 as suggested by Chin et al. (2003).
Accordingly, all reliability coefficients were found greater than the threshold value of 7, thus rendering the constructs deemed sufficiently reliable. Next, the convergent validity was assessed by using the average variance extracted (AVE) values, wherein all AVE values obtained were higher than .50 and indicated that the convergent validity of

Table 2

Results of the measurement model

\begin{tabular}{|c|c|c|c|c|c|}
\hline Constructs & Indicators & Loadings & Cronbach's Alpha & Composite Reliability & AVE \\
\hline \multirow[t]{5}{*}{ INT } & INT1 & 0.803 & .893 & .921 & .701 \\
\hline & INT2 & 0.862 & & & \\
\hline & INT3 & 0.840 & & & \\
\hline & INT4 & 0.869 & & & \\
\hline & INT5 & 0.808 & & & \\
\hline \multirow[t]{6}{*}{ PU } & PU1 & 0.796 & .890 & .916 & .646 \\
\hline & PU2 & 0.756 & & & \\
\hline & PU3 & 0.780 & & & \\
\hline & PU4 & 0.762 & & & \\
\hline & PU5 & 0.856 & & & \\
\hline & PU6 & 0.866 & & & \\
\hline \multirow[t]{2}{*}{ RA } & RA1 & 0.902 & .760 & .893 & .807 \\
\hline & RA2 & 0.894 & & & \\
\hline \multirow[t]{6}{*}{$\mathrm{COM}$} & COM1 & 0.871 & .943 & .955 & .778 \\
\hline & COM2 & 0.893 & & & \\
\hline & COM3 & 0.832 & & & \\
\hline & COM4 & 0.884 & & & \\
\hline & COM5 & 0.916 & & & \\
\hline & COM6 & 0.894 & & & \\
\hline \multirow[t]{5}{*}{ OBS } & OBS1 & 0.821 & .873 & .907 & .662 \\
\hline & OBS2 & 0.760 & & & \\
\hline & OBS3 & 0.842 & & & \\
\hline & OBS4 & 0.851 & & & \\
\hline & OBS5 & 0.791 & & & \\
\hline \multirow[t]{2}{*}{ SI } & SI1 & 0.956 & .909 & .957 & .917 \\
\hline & SI2 & 0.959 & & & \\
\hline \multirow[t]{5}{*}{ DC } & DC1 & 0.807 & .872 & .906 & .660 \\
\hline & DC2 & 0.754 & & & \\
\hline & DC3 & 0.890 & & & \\
\hline & DC4 & 0.833 & & & \\
\hline & DC5 & 0.770 & & & \\
\hline
\end{tabular}


Table 3

Heterotrait-Monotrait ratio (HTMT) analysis

\begin{tabular}{cccccccc}
\hline & COM & DC & INT & OBS & PU & RA & SI \\
\hline COM & & & & & & & \\
DC & 0.505 & & & & & \\
INT & 0.720 & 0.427 & & & & \\
OBS & 0.837 & 0.572 & 0.756 & & & \\
PU & 0.831 & 0.429 & 0.837 & 0.832 & & \\
RA & 0.759 & 0.492 & 0.661 & 0.840 & 0.793 & \\
SI & 0.842 & 0.502 & 0.763 & 0.849 & 0.829 & 0.724 \\
\hline
\end{tabular}

Table 4

Structural model assessment and hypothesis testing

\begin{tabular}{cccccccc}
\hline $\mathrm{H}$ & Path & Std. Beta & Std. Error & $t$-value & $p$-value & $f^{2}$ & Decision \\
\hline H1 & PU INT & .460 & 0.077 & $5.946^{* * *}$ & .000 & .178 & Supported \\
H2 & RA $\rightarrow$ INT & -.010 & 0.077 & 0.128 & .898 & .000 & NS \\
H3 & COM $\rightarrow$ INT & .041 & 0.092 & 0.447 & .655 & .001 & NS \\
H4 & OBS $\rightarrow$ INT & .166 & 0.092 & $1.804 *$ & .071 & .021 & Supported \\
H5 & SI INT & .194 & 0.080 & $2.412 * *$ & .016 & .029 & Supported \\
\hline Note. $* * * \mathrm{p}<.01, * * \mathrm{p}<.05, * \mathrm{p}<.10, \mathrm{R}^{2}=.615, \mathrm{Q}^{2}=.392$. & & & \\
\multicolumn{2}{l}{ Abbreviations: Hypothesis-H, Not Supported-NS. }
\end{tabular}

the constructs was well-established (Hair et al., 2017).

To assess the discriminant validity of the constructs, the Heterotrait-Monotrait ratio of correlations (HTMT) was used. According to Table 3, all the HTMT values displayed were below 0.90 , thus discriminant validity between any pair of the study constructs was established (Hair et al., 2017).

\section{Structural Model Assessment}

A structural model assessment was carried out using all 180 cases obtained. According to Table 4, the results reveal that only three out of five hypotheses are supported and yield significant relationships. In particular, perceived usefulness (PU) was found to generate a significant and positive relationship with the intention to use affiliate marketing PU $\rightarrow$ INT $(\beta=.460, p=.000)$. Similarly, the path of OBS $\rightarrow$ INT $(\beta=.166$, $p=.071)$ indicated that observability was also significant and positively associated with the intention to use affiliate marketing. Finally, the path of SI $\rightarrow$ INT $(\beta=.194$, $p=.016)$ confirmed the significant relationship between social influence and the intention to use affiliate marketing. Thus, $\mathrm{H} 1, \mathrm{H} 4$, and $\mathrm{H} 5$ were supported. In contrast, compatibility $(\beta=.041, p=.655)$ and relative advantage $(\beta=-.010, p=.898)$ were revealed to not significantly relate to the intention to use affiliate marketing. Hence, the $\mathrm{H} 2$ and $\mathrm{H} 3$ of this study were not accepted. In brief, it could be summarized that all predictor constructs were able to explain $61.5 \%$ 
$\left(\mathrm{R}^{2}=.615\right)$ of the total variance of the target construct, which was considered moderate in this particular case. Further investigation of the effect size revealed that the $f^{2}$ values of perceived usefulness (.178) have a medium significant effect on the intention to use affiliate marketing whereas observability (.021) and social influence (.029) have small significant effects on the intention to use affiliate marketing. Meanwhile, the predictive relevance of the model was greater than zero $\left(\mathrm{Q}^{2}=.392\right)$, indicating that it yielded predictive ability.

\section{Moderation Analysis}

The current study adopted a two-stage approach (Chin et al., 2003) geared for testing the effects of the moderating construct. The analysis was initiated by multiplying the items of developmental culture (DC) with those of the predictor constructs so as to create the interaction items for the prediction of the intention to use affiliate marketing (INT). Table 5 displays the results of moderation analysis obtained, wherein the paths of DC*PU $\rightarrow$ INT $(\beta=-$ $.207, p=.009)$ and $\mathrm{DC} * \mathrm{COM} \rightarrow \operatorname{INT}(\beta=.292$, $p=.002)$ indicate that developmental culture moderates the relationship between (PU and INT) and (COM and INT). Figures 2 and 3 show the moderation graphs of the results. The interaction term (DC*PU) and INT in Figure 2 reported a negative path coefficient $(\beta=-.207)$, which suggests that the lower the developmental culture, the stronger the relationship between perceived usefulness and intention to use affiliate marketing. On the other hand, the interaction term (DC*COM) and INT in Figure 3 reported a positive path coefficient $(\beta=.292)$, which indicates that the higher the developmental culture, the stronger the relationship between compatibility and intention to use affiliate marketing. As such, H6a and H6c are supported.

\section{DISCUSSIONS}

\section{Results Discussion}

According to the statistical results obtained, perceived usefulness $(\beta=.460, p=.000)$ was found to be significantly and positively associated with the intention to use affiliate marketing, which was in line with the information offered by Haq (2012) and Nagy (2018). Here, it can be understood

Table 5

Results of the moderation analysis

\begin{tabular}{ccccccc}
\hline $\mathrm{H}$ & Path & Std. Beta & Std. Error & $t$-value & $p$-value & Decision \\
\hline H6a & DC*PU $\rightarrow$ INT & -.207 & 0.079 & $2.608^{* *}$ & .009 & Supported \\
H6b & DC*RA $\rightarrow$ INT & -.098 & 0.061 & 1.612 & .108 & NS \\
H6c & DC COM $\rightarrow$ INT $^{*}$ & .292 & 0.094 & $3.088^{* *}$ & .002 & Supported \\
H6d & DC*OBS $\rightarrow$ INT & -.086 & 0.100 & 0.861 & .389 & NS \\
H6e & DC*SI $\rightarrow$ INT & .070 & 0.095 & 0.737 & .461 & NS \\
\hline
\end{tabular}

Note. $* * * \mathrm{p}<.01, * * \mathrm{p}<.05, * \mathrm{p}<.10, \mathrm{R}^{2}=.644$.

Abbreviations: Hypothesis-H, Not Supported-NS 


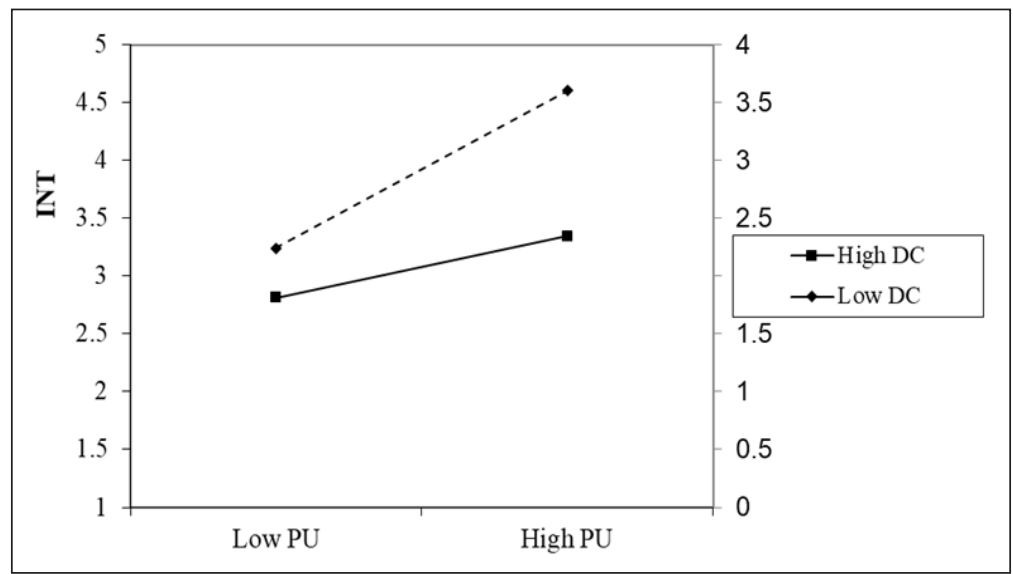

Figure 2. Developmental culture moderates the relationship between perceived usefulness and the intention to use affiliate marketing

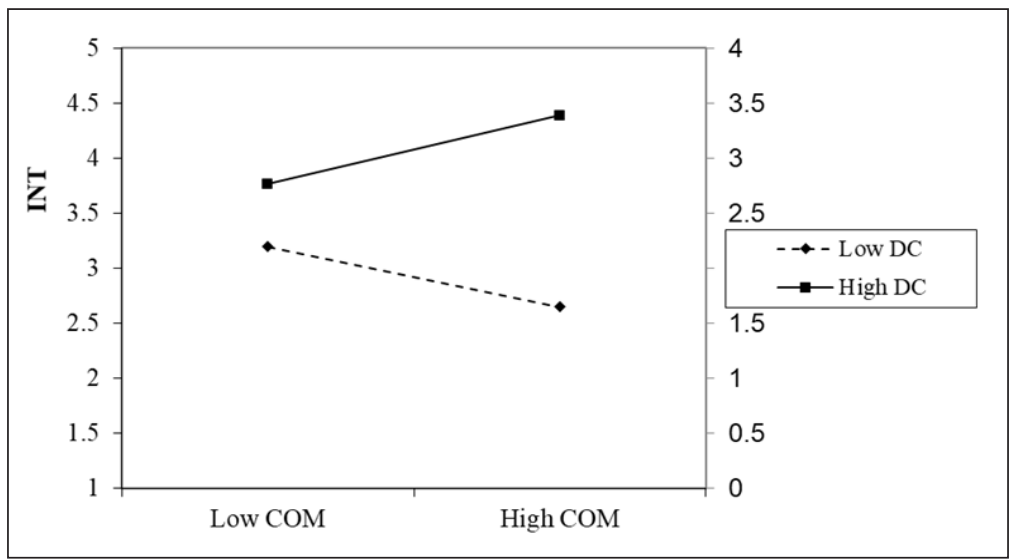

Figure 3. Developmental culture moderates the relationship between compatibility and the intention to use affiliate marketing

that the presence of useful technological attributes is especially critical in ensuring SMEs are able to source greater benefits, such as cost-saving, time efficiency, low effort, and high return. Moreover, Thaker (2018) has provided further evidence in the context of Malaysian SMEs, noting that the adoption of new technology is strongly influenced by perceived usefulness as it minimizes the required effort and improves work performance.
Next, the outcomes obtained showed the significance of social influence $(\beta=.194$, $p=.016)$ as a predictor of the intention to use affiliate marketing among SMEs in Malaysia. A past study by Abbas et al. (2018) had presented a strong argument in support of this finding: people working in such organizations perceive the importance for their companies to employ affiliate marketing in the same manner in which their customers, business partners, and other 
same-sector counterparts are using it. From a different point of view, Suchada et al. (2018) have offered detailed explanations regarding the relevance of word-of-mouth and electronic word-of-mouth in inducing an individual's intention to use new technology. This is attributable to the aspect of technology adoption among potential users that is largely determined by social influence.

Further, the analysis carried out also revealed that the element of observability $(\beta=.166, p=.071)$ was significantly correlated with the intention to use affiliate marketing. This notion is approached in the sense wherein the higher the level of understanding one has regarding the technology effectiveness, the higher the likelihood that they will adopt the technology (AlSharji et al., 2018; Chauhan et al., 2018; Rogers, 2003). In line with this, Ramayah et al. (2016) have further emphasized that if SMEs are able to see the benefits of technology, which include an increase in productivity, sales growth, higher customer satisfaction, and retention, then they are more likely to implement the technology.

On the contrary, compatibility $(\beta=.041$, $p=.655$ ) was found to be not significantly linked to the intention to use affiliate marketing, which contrasted the opinions positioned by studies such as Samat et al. (2017) and Sandu et al. (2017). Therefore, this finding may be plausibly explained by the manner in which the respondents may perceive the tool to be inconsistent with their work values, past experience, and current needs.
Moreover, this study revealed that relative advantage $(\beta=-.010, p=.898)$ was not a significant predictor of affiliate marketing. In line with this, Rogers (2003) has argued that new technology may not suitably fit certain individual needs and consequently fail to result in perceived relative advantage beyond the current technologies. Such a situation often happens when people or potential users are unsure of any relative advantage offered by the new technology, thus rendering them hesitant and against utilizing it.

Finally, hypothesis testing results obtained in this study showed that developmental culture moderated two of the paths included in the research model (i.e., DC*PU $\rightarrow$ INT and $\mathrm{DC}^{*} \mathrm{COM} \rightarrow \mathrm{INT}$ ). Therefore, this is indicative of the stronger impact aided by perceived usefulness and compatibility toward the intention to use affiliate marketing among SMEs under the influence of the moderator element. These findings are in support of the previous argument by J.-C. Lee et al. (2017), which positions developmental culture and its role in increasing the rate of technology adoption. Additionally, the outcomes parallel the explanation offered by Quinn and Kimberly (1984), whereby the culture is construed as highly flexible, external-oriented, and capable of driving technology development. As noted by Rai (2011), developmental culture focuses on external opportunities and the cultural characteristics of creativity and flexibility, which can enable firms to identify and acquire external knowledge effectively. This study also shows that when 
an individual company is characterized by developmental culture, the impact of perceived usefulness and compatibility on the intention to use affiliate marketing will be more reliable.

\section{Theoretical Implications}

The theoretical implications of this study can be noticed based on the introduction of developmental culture as a moderator between the predictors and the target construct. By using the orthogonalizing approach, this study asserts that developmental culture act as a full moderator in the model to moderate two relationships in the research model. The first relationship involves perceived usefulness and intention to use affiliate marketing while the second relationship addresses the compatibility and intention to use affiliate marketing. Based on these results, this study has contributed to future studies in utilizing developmental culture as a potential moderator to examine the extent of changes in findings at interval times. Moreover, the questionnaire of this research is developed based on the theories used, with the validation of the research instruments in this study generally acceptable and can be used extensively.

\section{Managerial Implications}

The findings of this study underlined perceived usefulness as the most essential factor necessary for managerial actions, thus calling for SME owners, managers, and affiliates to focus on it in supporting their intention to use affiliate marketing. For example, affiliate marketing-related services must deliver valuable propositions rendering sale transactions more effective and generating extra benefits to their users. Therefore, this can be attained by ensuring different online marketing features are personalized and in accordance with the past experiences and preferences of users themselves, whereas any extraneous procedures must be isolated to speed up the processes and provide efficient end results. In this particular regard, the government can provide extra information, special programs, and professional training to the owners, managers, and affiliates in ensuring they gain maximum benefits of affiliate marketing.

\section{CONCLUSION}

Throughout the past years, studies have been conducted to investigate factors influencing the adoption of online marketing. However, within the context of affiliate marketing, there is a lack of studies that have investigated the factors influencing the intention to use affiliate marketing, particularly in the context of manufacturing SMEs. This study has, therefore, contributed to the extant research of intention to use affiliate marketing by using various theories of technology acceptance model (Davis, 1989), diffusion of innovation (Rogers, 1983), the unified theory of acceptance and use of technology (Venkatesh et al., 2003), as well as the competing values framework (Quinn \& Kimberly, 1984). 


\section{Limitations and Future Research}

First, the scope of this study is limited to four major states in Malaysia, thus possibly suggesting that the issue of generalizability may arise as SMEs located in other states are excluded. Therefore, any future efforts are suggested to expand the study scope and cover other major cities in the country in an all-encompassing manner. Second, the predictor constructs used in this study are not comprehensive, potentially necessitating future studies to add more relevant determinants into the research model for improved model predictability. Third, the effects of the determining factors associated with change over time are not addressed in this study, thus possibly requiring future researchers to conduct longitudinal studies in the bid to address the effects of change over time on the target construct. Finally, the use of a mixed-method approach combining both qualitative and quantitative methods can further aid future researchers in developing a more comprehensive research model.

\section{ACKNOWLEDGEMENTS}

The authors wish to thank the Malaysian Ministry of Higher Education and Universiti Teknologi Malaysia (GUP Tier 2: 15J99) for providing financial support to publish this paper.

\section{REFERENCES}

Abbas, S., Hassan, H., Asif, J., Junaid, H., \& Zainab, F. (2018). What are the key determinants of mobile banking Adoption in Pakistan? International
Journal of Scientific \& Engineering Research, 9(2), 841-848. https://doi.org/10.14299/ ijser.2018.02.012

Abdat, F. A. (2020). Using UTAUT model to predict social media adoption among Indonesian SMEs. Saudi Journal of Economics and Finance, 4(10), 498-505. https://doi.org/10.36348/sjef.2020. v04i10.003

Adnan, N., Nordin, S. M., \& Rasli, A. M. (2019). A possible resolution of Malaysian sunset industry by green fertilizer technology: Factors affecting the adoption among paddy farmers. Environmental Science and Pollution Research, 26(26), 27198-27224. https://doi.org/10.1007/ s11356-019-05650-9

Alam, S. S., Khatibi, A., Ahmad, M. I., \& Ismail, H. B. (2008). Factors affecting e-commerce adoption in the electronic manufacturing companies in Malaysia. International Journal of Commerce and Management, 17(1/2), 125-139. https://doi. org/ 10.1108/10569210710776503.

AlSharji, A., Ahmad, S. Z., \& Abu Bakar, A. R. (2018). Understanding social media adoption in SMEs: Empirical evidence from the United Arab Emirates. Journal of Entrepreneurship in Emerging Economies, 10(2), 302-328. https:// doi.org/ 10.1108/JEEE-08-2017-0058.

Batra, S., \& Arora, D. A. (2020). Adoption of ecommerce in MSME sector. PalArch's Journal of Archaeology of Egypt/Egyptology, 17(9), 5701-5710.

Belete, S., \& Tsegaye, M. (2018). Does behavior of clients matter in adoption of internet banking? Evidence from Commercial Bank of Ethiopia. Journal of Economics and International Finance, 10(6), 58-64. https://doi.org/10.5897/ JEIF2018.0901.

Beranek, L. (2018). An empirical investigation of factors that influence commitment and active participation in in-house affiliate marketing 
network. International Journal of Electronic Business, 14(3), 189-211. https://doi.org/ 10.1504/IJEB.2018.095957.

Beranek, L. (2019). The development of an in-house affiliate marketing network - A case study. International Journal of Internet Marketing and Advertising, 13(3), 271-283. https://doi. org/10.1504/ijima.2019.102580

Cameron, K. S., \& Quinn, R. E. (2011). Diagnosing and changing organizational culture: Based on the competing values framework (3rd ed.). Jossey-Bass.

Chauhan, S., Mukhopadhyay, S., \& Jaiswal, M. (2018). The adoption of mobile app for B2C transaction in platform marketplace: An empirical examination of key drivers. Journal of Information Technology Case and Application Research, 20(1), 1-14. https://doi. org/ 10.1080/15228053.2018.1453338.

Cheung, C. M. K., Chiu, P.-Y., \& Lee, M. K. O. (2011). Online social networks: Why do students use Facebook? Computers in Human Behavior, 27(4), 1337-1343. https://doi.org/ 10.1016/j. chb.2010.07.028.

Chin, W. W., Marcolin, B. L., \& Newsted, P. R. (2003). A Partial Least Squares latent variable modeling approach for measuring interaction effects: Results from a Monte Carlo simulation study and an electronic-mail emotion/adoption study. Information Systems Research, 14(2), 189-217. https://doi.org/ 10.1287/isre.14.2.189.16018

Cohen, J. (1992). A power primer. Psychological Bulletin, 112(1), 155-159. https://doi. org/10.1037/0033-2909.112.1.155.

Davis, F. D. (1989). Perceived usefulness, perceived ease of use, and user acceptance of information technology. MIS Quarterly, 13(3), 319-340. https://doi.org/ 10.2307/249008.

Department of Statistics Malaysia. (2018). Small and Medium Enterprises (SMEs) performance 2017. https://www.dosm.gov.my/v1/index.php.
Dwivedi, Y. K., Rana, N. P., \& Alryalat, M. A. A. (2017). Affiliate marketing: An overview and analysis of emerging literature. The Marketing Review, 17(1), 33-50. https://doi.org/ 10.1362/1 46934717X14909733966092.

Fox, P., \& Wareham, J. (2010). Governance mechanisms in internet-based affiliate marketing programs in Spain. International Journal of e-Business Research, 6(1), 1-18. https://doi.org/ 10.4018/978-1-61350-462-8.ch014.

Ghobakhloo, M., Hong, T. S., Sabouri, M. S., \& Zulkifli, N. (2012). Strategies for successful information technology adoption in small and medium-sized enterprises. Information, 3, 36-67. https://doi.org/ 10.3390/info3010036.

Gregori, N., Daniele, R., \& Altinay, L. (2014). Affiliate marketing in tourism: Determinants of consumer trust. Journal of Travel Research, 53(2), 196-210. https://doi.org/ 10.1177/0047287513491333.

Haikal, E. K., Freihat, S. M., Adnan, M., Joudeh, J. M. M., \& Hashem, T. N. (2020). The role of supply chain strategy and affiliate marketing in increasing the demand for e-commerce. Social media POV, 9(1), 832-844.

Hair, J. F., Hult, G. T. M., Ringle, C. M., \& Sarstedt, M. (2017). A primer on Partial Least Squares Structural Equation Modeling (PLS-SEM) (2nd ed.). Sage Publications, Inc.

Haq, Z. U. (2012). Affiliate marketing programs: A study of consumer attitude towards affiliate marketing programs among Indian users. International Journal of Research Studies in Management, 1, 127-137. https://doi.org/ 10.5861/ijrsm.2012.v1i1.84.

Houghton, S., Moss, M., \& Casey, E. (2020). Affiliate marketing of sports betting - A cause for concern? International Gambling Studies, 20(2), 240-245. https://doi.org/10.1080/144597 95.2020.1718737

Huang, Q., Fang, K., \& Liu, H. (2013). The moderating role of organizational culture in the relationship 
between power, trust, and e-SCMS adoption intention. PACIS 2013 Proceedings, 213.

Jalali, M. S., Kaiser, J. P., Siegel, M., \& Madnick, S. (2019). The internet of things (IoT) promises new benefits and risks: A systematic analysis of adoption dynamics of IoT products. IEEE Security and Privacy, 17(2), 39-48. https://doi. org/10.1109/msec.2018.2888780

Karjaluoto, H., \& Taiminen, H. M. (2015). The usage of digital marketing channels in SMEs. Journal of Small Business and Enterprise Development, 22(4), 633-651. https://doi.org/ 10.1108/JSBED-05-2013-0073

Lee, J.-C., Chen, C.-Y., \& Shiue, Y.-C. (2017). The moderating effects of organisational culture on the relationship between absorptive capacity and software process improvement success. Information Technology and People, 30(1), 4770. https://doi.org/10.1108/ITP-09-2013-0171

Lee, S. (2018). Enhancing customers' continued mobile app use in the service industry. Journal of Services Marketing, 32(6), 680-691. https:// doi.org/10.1108/JSM-01-2017-0015.

Lou, L., Tian, Z., \& Koh, J. (2017). Tourist satisfaction enhancement using mobile QR code payment: An empirical investigation. Sustainability, 9(7), 1186. https://doi.org/ 10.3390/su9071186.

Mairura, K. O. (2016). Relative advantage as a determinant of technology adoption among automobile mechanics in micro and small enterprises in Kenya. International Journal Academic Research in Business and Social Sciences, 21(5), 86-92.

Maksimovic, M. (2018). Greening the future: Green internet of things (G-IoT) as a key technological enabler of sustainable development. The Internet of Things and Big Data Analytics toward NextGeneration Intelligence, 30, 283-313. https://doi. org/ 10.1007/978-3-319-60435-0_12.

Mazurek, G., \& Kucia, M. (2011, September 1-3). Potential of affiliate marketing [Paper presentation]. 7th International Conference Management of Technological Changes, Alexandroupolis, Greece.

Mbiadjo, F. F. M., \& Djeumene, P. (2015). Factors explaining the adoption of mobile marketing in Cameroon: Exploratory study on the use of SMS as method of transmission of social information. African Journal of Marketing Management, 7(2), 20-31. https://doi.org/ 10.5897/AJMM2014.0430.

Merchant, S. (2007). Exploring the influence of cultural values on the acceptance of information technology: An application of the technology acceptance model. Informing Science and Information Technology, 4, 430-443.

Nagy, J. T. (2018). Evaluation of online video usage and learning satisfaction: An extension of the technology acceptance model. The International Review of Research in Open and Distributed Learning, 19(1), 160-185. https://doi.org/ 10.19173/irrodl.v19i1.2886.

Newton, S., \& Ojo, M. (2018). Driving traffic and customer activity through affiliate marketing: Understanding and addressing the differences between affiliate marketing. In S. Singh (Ed.), Driving traffic and customer activity through affiliate marketing (pp. 101-112). IGI Global. https://doi.org/10.4018/978-1-5225-2656-8. ch007

Okafor, D. J, Nico, M., \& Azman, B. B. (2016). The influence of perceived ease of use and perceived usefulness on the intention to use a suggested online advertising workflow. Canadian International Journal of Science and Technology, 6(14), 162-174.

Poorangi, M. M., Khin, E. W. S., Nikoonejad, S., \& Kardevani, A. (2013). E-commerce adoption in Malaysian small and medium enterprises practitioner firms: A revisit on Rogers' model. Annals of the Brazilian Academy of Sciences, 85(4), 1593-1604. https://doi.org/ 10.1590/000137652013103512 . 
Quinn, R. E., \& Kimberly, J. R. (1984). Paradox, planning, and perseverance: Guidelines for managerial practice. In J. R. Kimberley \& R. E. Quinn (Eds.), Managing organizational transitions (pp. 295-313). Irwin.

Quinn, R. E., \& Spreitzer, G. M. (1991). The psychometrics of the competing values culture instrument and an analysis of the impact of organization culture on quality of life. Research in Organizational Change Development, 5, 115-142.

Rahaman, S. U., Badugula, N. M., Wang, T.W., \& Somarajan, N. C. (2018). The current development of technology model in e-commerce and suggestion for future research. MWAIS 2018 Proceedings, 1-7.

Rahi, S., Abd. Ghani, M., Alnaser, F. M., \& Ngah, A. H. (2018). Investigating the role of unified theory of acceptance and use of technology (UTAUT) in internet banking adoption context. Management of Information Management, 8(3), 173-186. https://doi.org/ 10.1108/WJSTSD-05-2018-0040.

Rai, R. K. (2011). Knowledge management and organizational culture: A theoretical integrative framework. Journal of Knowledge Management, 15(5), 779-801. https://doi. org/10.1108/13673271111174320.

Ramachandran, A. T., Ahmad, N., Miskon, S., \& Iahad, N. A. (2019). Factors influencing the adoption of social media in service sector small and medium enterprises (SMEs). Advances in Intelligent Systems and Computing, 1073 (July), 917-925. https://doi.org/10.1007/978-3-03033582-3_86

Ramayah, T., Ling, N. S., Taghizadeh, S. K., \& Rahman, S. A. (2016). Factors influencing SMEs website continuance intention in Malaysia. Telematics and Informatics, 33(1), 150-164. https://doi.org/ 10.1016/j.tele.2015.06.007.

Rogers, E. M. (1983) Diffusion of innovations (3rd ed). Free Press, Collier Macmillan.
Rogers, E. M. (2003). Diffusion of innovations (5th ed.). Free Press, Collier Macmillan.

Samat, M. F., Yusoff, N. H., Ismail, M., Annual, N., \& Mamat, M. (2017). Technological factor and social media marketing adoption among SMEs in Kelantan. Proceedings of the 2nd International Conference on Economic Education and Entrepreneurship, 456-461. https://doi.org/ $10.5220 / 0006887904560461$.

Sandu, R., Gide, E., \& Karim, S. (2017). The impact of innovatives strategies to influence the adoption of cloud based service success in Indian small and medium enterprises (SMEs). International Journal of Art and Sciences, 10(2), 389-400.

Saunders, M. N. K., Lewis, P., \& Thornhill, A. (2009). Research methods for business students (5th ed.). Prentice Hall.

Shaltoni, A. M. (2017). From websites to social media: Exploring the adoption of internet marketing in emerging industrial markets. Journal of Business and Industrial Marketing, 32(7), 1009-1019. https://doi.org/ 10.1108/JBIM-06-2016-0122.

Singhal, K., \& Anand, A. (2021). Analysis of YouTube channel analytics and affiliate marketing with operating system. In G. S. Hura, A. K. Singh, \& L. S. Hoe (Eds.), Advances in communication and computational technology (pp. 1527-1537). Springer. https://doi.org/10.1007/978-981-155341-7_117

SME Corporation Malaysia. (2018). SME annual report 2017/18. https://www.smecorp.gov.my/ index.php/en/laporan-tahunan/3342-laporantahunan-pks-2017-18

Suchada, J., Watanapa, B., Charoenkitkarn, N., \& Chirapornchai, T. (2018). Hotels and resorts rent intention via online affiliate marketing. $K n E$ Social Sciences, 3(1), 132-142. https://doi.org/ 10.18502/kss.v3i1.1402.

Sun, S., Cegielski, C. G., Jia, L., \& Hall, D. J. (2018). Understanding the factors 
affecting the organizational adoption of big data. Journal of Computer Information Systems, 58(3), 193-203. https://doi.org/ 10.1080/08874417.2016.1222891.

Suryanarayana, S. A., Sarne, D., \& Kraus, S. (2019). Information disclosure and partner management in affiliate marketing. Proceedings of the First International Conference on Distributed Artificial Intelligence, 1-8. https:// doi.org/10.1145/3356464.3357703

Thaker, M. A. B. M. T. (2018). Modelling SMEs' behavioral intention to adopt Islamic crowdfunding-small and medium enterprises (ICSMES) model as a source of financing in Malaysia. Journal of Islamic Monetary Economics and Finance, 4(2), 293-310. https:// doi.org/ 10.21098/jimf.v4i2.961.

Thiesse, F., Staake, T., Schmitt, P., \& Fleisch, E. (2011). The rise of the "next-generation bar code: An international RFID adoption study. Supply Chain Management International Journal, 16(5), 328-345. https://doi.org/ $10.1108 / 13598541111155848$.

Tian, M., Deng, P., Zhang, Y., \& Salmador, M. P. (2018). How does culture influence innovation? A systematic literature review. Management Decision, 56(5), 1088-1107. https://doi.org/ 10.1108/MD-05-2017-0462.
Venkatesh, V., Morris, M. G., Davis, G. B., \& Davis, F. D. (2003). User acceptance of information technology: Toward a unified view. MIS Quarterly, 27(3), 425-478. https://doi.org/ $10.2307 / 30036540$.

Venkatesh, V., Thong, J. Y. L., \& Xu, X. (2012). Consumer acceptance and use of information technology: Extending the unified theory of acceptance and use of technology. MIS Quarterly, 36(1), 157-178.

Zain, Z. M., Jusoh, A. A., Munir, R. I. S., \& Putit, L. (2020). Drivers of E-Commerce Adoption amongst Small \& Medium Sized Enterprises (SMEs) in the Business Service Sector. Journal of International Business, Economics and Entrepreneurship, 5(1), 50-58.

Zhang, S., \& Cabage, N. (2017). Search engine optimization: Comparison of link building and social sharing. Journal of Computer Information Systems, 57(2), 148-159. https://doi.org/ 10.1080/08874417.2016.1183447.

Zolkepli, I. A., \& Kamarulzaman, Y. (2015). Social media adoption: The role of media needs and innovation characteristics. Computers in Human Behavior, 43, 189-209. https://doi.org/ 10.1016/j. chb.2014.10.050. 


\section{APPENDIX}

Supplementary Table

Measures for the study constructs

\begin{tabular}{|c|c|c|c|}
\hline Constructs & & Measurement Items & Source \\
\hline \multirow[t]{5}{*}{$\begin{array}{l}\text { Intention to use } \\
\text { affiliate marketing } \\
\text { (INT) }\end{array}$} & INT1 & $\begin{array}{l}\text { An affiliate content publisher will be } \\
\text { the prospective sellers of our company's } \\
\text { products and services in the future. }\end{array}$ & $\begin{array}{l}\text { Mazurek and Kucia } \\
\text { (2011) and Ramayah et } \\
\text { al. (2016) }\end{array}$ \\
\hline & INT2 & $\begin{array}{l}\text { We plan to hire an affiliate content } \\
\text { publisher to convince clients to buy our } \\
\text { products and services. }\end{array}$ & \\
\hline & INT3 & $\begin{array}{l}\text { We feel an affiliate content publisher is } \\
\text { influential when it comes to convincing } \\
\text { clients to buy our products and services. }\end{array}$ & \\
\hline & INT4 & $\begin{array}{l}\text { If we had a choice, we would outsource } \\
\text { the selling of our products to an affiliate } \\
\text { content publisher. }\end{array}$ & \\
\hline & INT5 & $\begin{array}{l}\text { We feel hiring an affiliate content publisher } \\
\text { is a wise idea. }\end{array}$ & \\
\hline \multirow[t]{6}{*}{$\begin{array}{l}\text { Perceived Usefulness } \\
(\mathrm{PU})\end{array}$} & PU1 & $\begin{array}{l}\text { Our company uses affiliate marketing to } \\
\text { reach a wider base of internet users and } \\
\text { shoppers. }\end{array}$ & $\begin{array}{l}\text { Alam et al. (2008) and } \\
\text { Nagy (2018) }\end{array}$ \\
\hline & PU2 & $\begin{array}{l}\text { Our company uses affiliate marketing to } \\
\text { reduce the cost needed to sell our products } \\
\text { and services. }\end{array}$ & \\
\hline & PU3 & $\begin{array}{l}\text { Our company uses affiliate marketing } \\
\text { to improve the quality of our marketing } \\
\text { strategy. }\end{array}$ & \\
\hline & PU4 & $\begin{array}{l}\text { Our company uses affiliate marketing } \\
\text { to support every critical aspect of our } \\
\text { marketing model. }\end{array}$ & \\
\hline & PU5 & $\begin{array}{l}\text { Our company uses affiliate marketing to } \\
\text { increase our marketing performance. }\end{array}$ & \\
\hline & PU6 & $\begin{array}{l}\text { Overall, our company uses affiliate } \\
\text { marketing to assist in the sale of our } \\
\text { products and services. }\end{array}$ & \\
\hline \multirow[t]{2}{*}{$\begin{array}{l}\text { Relative Advantage } \\
\text { (RA) }\end{array}$} & RA1 & $\begin{array}{l}\text { Affiliate marketing helps our company to } \\
\text { reduce its direct and indirect costs of the } \\
\text { business. }\end{array}$ & $\begin{array}{l}\text { Ghobakhloo et al. } \\
\text { (2012) and Shaltoni et } \\
\text { al. (2018) }\end{array}$ \\
\hline & RA2 & $\begin{array}{l}\text { Affiliate marketing helps our company to } \\
\text { improve its processes. }\end{array}$ & \\
\hline \multirow[t]{3}{*}{$\begin{array}{l}\text { Compatibility } \\
(\mathrm{COM})\end{array}$} & COM1 & $\begin{array}{l}\text { Affiliate marketing fits well with the way } \\
\text { our company works. }\end{array}$ & $\begin{array}{l}\text { Jaafar et al. (2015) and } \\
\text { Thiesse et al. (2011) }\end{array}$ \\
\hline & COM2 & $\begin{array}{l}\text { Affiliate marketing is in line with the } \\
\text { personality of our company. }\end{array}$ & \\
\hline & COM3 & $\begin{array}{l}\text { Affiliate marketing is compatible with the } \\
\text { company's current IT infrastructure. }\end{array}$ & \\
\hline
\end{tabular}


Supplementary Table (continue)

\begin{tabular}{|c|c|c|c|}
\hline \multirow[t]{4}{*}{ Constructs } & \multicolumn{2}{|r|}{ Measurement Items } & \multirow[t]{2}{*}{ Source } \\
\hline & COM4 & $\begin{array}{l}\text { Affiliate marketing is appropriate for the } \\
\text { IT infrastructure of our company. }\end{array}$ & \\
\hline & COM5 & $\begin{array}{l}\text { Affiliate marketing is consistent with our } \\
\text { business strategy. }\end{array}$ & \\
\hline & COM6 & $\begin{array}{l}\text { Affiliate marketing fits with the work style } \\
\text { of the company. }\end{array}$ & \\
\hline \multirow[t]{5}{*}{ Observability (OBS) } & OBS1 & $\begin{array}{l}\text { Our company does not have difficulty } \\
\text { telling others about the results of using } \\
\text { affiliate marketing. }\end{array}$ & $\begin{array}{l}\text { Alam et al. (2008) and } \\
\text { Lou et al. (2017) }\end{array}$ \\
\hline & OBS2 & $\begin{array}{l}\text { Affiliate marketing improves the quality of } \\
\text { our work for the same amount of effort. }\end{array}$ & \\
\hline & OBS3 & $\begin{array}{l}\text { Our company could communicate with } \\
\text { others about the consequences of using } \\
\text { affiliate marketing. }\end{array}$ & \\
\hline & OBS4 & $\begin{array}{l}\text { The results of using affiliate marketing are } \\
\text { apparent to our company. }\end{array}$ & \\
\hline & OBS5 & $\begin{array}{l}\text { Affiliate marketing reduces the time to } \\
\text { handle our advertising and promotion } \\
\text { tasks. }\end{array}$ & \\
\hline \multirow[t]{2}{*}{ Social Influence (SI) } & SI1 & $\begin{array}{l}\text { Our business partners strongly support } \\
\text { affiliate marketing in our company. }\end{array}$ & $\begin{array}{l}\text { Rahi et al. (2018) and } \\
\text { Venkatesh et al. (2012) }\end{array}$ \\
\hline & SI2 & $\begin{array}{l}\text { In general, our company supports affiliate } \\
\text { marketing. }\end{array}$ & \\
\hline \multirow[t]{5}{*}{$\begin{array}{l}\text { Developmental } \\
\text { Culture (DC) }\end{array}$} & $\mathrm{DC} 1$ & $\begin{array}{l}\text { Our company is a very dynamic and } \\
\text { entrepreneurial place to work. }\end{array}$ & Lee et al. (2017) \\
\hline & DC2 & $\begin{array}{l}\text { The leadership of our company is willing } \\
\text { to exemplify innovation and risk-taking. }\end{array}$ & \\
\hline & DC3 & $\begin{array}{l}\text { Our company emphasizes acquiring new } \\
\text { resources and creating new challenges. }\end{array}$ & \\
\hline & DC4 & $\begin{array}{l}\text { Our company is willing to try new } \\
\text { technologies to get valuable opportunities. }\end{array}$ & \\
\hline & DC5 & $\begin{array}{l}\text { Our company defines success based on } \\
\text { having the newest technologies. }\end{array}$ & \\
\hline
\end{tabular}


